\title{
Biomarkers in predicting mortality and treatment in hemodialysis patients
}

\author{
Angela Yee-Moon Wang
}

Address: Department of Medicine, Queen Mary Hospital, University of Hong Kong, 102 Pok Fu Lam Road, Hong Kong

Email: aymwang@hku.hk

FI000 Medicine Reports 2009, I:2I (doi: 10.34I0/MI-2I)

The electronic version of this article is the complete one and can be found at: http://FI000.com/Reports/Medicine/content/I/2I

\begin{abstract}
Circulating natriuretic peptides are useful biomarkers of left ventricular dysfunction and heart failure in the general population. Cardiac troponin $\mathrm{T}(\mathrm{cTnT})$ is also considered a sensitive marker of myocardial injury. However, the fact that levels of circulating natriuretic peptides and cTnT are almost invariably increased in end-stage renal disease patients has been considered a major limitation for their use as diagnostic or prognostic tools in this population. We provide an updated review on the role of natriuretic peptides and $\mathrm{cTnT}$ as biomarkers in predicting outcome and treatment in the hemodialysis population.
\end{abstract}

\section{Introduction and context}

Cardiovascular disease is the leading cause of mortality in patients with end-stage renal disease (ESRD) and is partly attributed to the very high prevalence of left ventricular (LV) abnormalities, including LV hypertrophy, systolic dysfunction and congestive heart failure. The Kidney Disease Outcome Quality Initiative (KDOQI) guidelines have, therefore, made the recommendation that echocardiography be performed at initiation of dialysis in all ESRD patients and every 3 years thereafter [1]. However, echocardiography services are very often stretched in hospitals and not routinely performed in most dialysis centers. Therefore, circulating biomarkers that identify patients with subclinical heart disease or diseased myocardium may have a potentially important clinical value in allowing early detection, intervention and possibly ongoing surveillance of highrisk patients. In recent years, the natriuretic peptides have emerged as promising cardiac biomarkers in this aspect.

The B-type, or brain natriuretic peptide (BNP) is a 32 amino acid peptide hormone predominantly released from the ventricles in response to $L V$ volume expansion and pressure overload [2-4] and has a circulating halflife of 23 minutes. N-terminal pro-BNP (NT-pro-BNP) is a 76 amino acid peptide hormone also cleaved from the prohormone; it is biologically inactive but has a much longer half-life (120 minutes). BNP levels are well known to correlate with $\mathrm{LV}$ filling pressures and are elevated in patients with LV dysfunction $[2,5]$. Both BNP and NT-pro-BNP levels increased in proportion to the severity of heart failure as assessed using the New York Heart Association classification in the general population $[6,7]$. In patients without chronic kidney disease (CKD), BNP and NT-pro-BNP testing are found to be most useful in ruling out the diagnosis of heart failure in those presenting with dyspnoea [8-11]. The value of BNP or NT-pro-BNP testing in predicting prognosis has also been established in the general population [12].

In stage $5 \mathrm{CKD}$ patients receiving hemodialysis or peritoneal dialysis, BNP and NT-pro-BNP are almost invariably increased compared to normal cutoffs [1319]. These elevations were partly attributed to decreased renal clearance, chronic volume overload as well as to the very high prevalence of cardiac abnormalities [13-19]. NT-pro-BNP has been shown to be inversely related to residual renal function in both hemodialysis and peritoneal dialysis patients $[15,16]$. A study in the nonESRD population also confirmed renal dysfunction as a 
potential cause of markedly elevated BNP and NT-proBNP in the absence of LV systolic dysfunction [20]. Thus, in dialysis patients, BNP and NT-pro-BNP levels have to be interpreted in light of the presence or absence of residual renal function. BNP and NT-pro-BNP have been shown to be strongly associated with LV hypertrophy and dilation, and systolic dysfunction, in both hemodialysis and peritoneal dialysis patients [14-19]. NT-proBNP was also associated with coronary artery disease in non-dialysis CKD patients [21].

On the other hand, cardiac troponin $\mathrm{T}$ (cTnT) is a sensitive marker of myocardial injury and is the current gold standard test for diagnosis of acute myocardial necrosis in the general population. However, levels of cTnT are frequently elevated in the absence of acute coronary syndrome among patients with varying degrees of kidney disease [22-28]. Using the $99^{\text {th }}$ percentile cutoff of $0.1 \mu \mathrm{g} / \mathrm{L}$, the prevalence of cTnT elevation was reported to range from 30 to $85 \%$ in ESRD patients [2227]. This led to the initial suggestion that cTnT may have limited diagnostic or prognostic value in patients with CKD. In the GUSTO IV (Global Use of Strategies to Open Occluded Coronary Arteries IV) trial, elevated cTnT was strongly predictive of poor short-term prognosis irrespective of creatinine clearance in patients with suspected acute coronary syndrome [29]. Notably, cTnT elevation had even greater prognostic importance among patients with mild to moderate degrees of kidney disease, clearly confirming the specificity of CTnT as a marker of myocardial injury among patients with kidney disease.

There is robust evidence that cTnT is a powerful prognostic marker in ESRD patients. One of the earliest and largest studies, by Apple et al. [26], showed that an elevated $c$ TnT $>99^{\text {th }}$ percentile cutoff was predictive of both short-term and long-term mortality in hemodialysis patients. Numerous other studies have demonstrated similar prognostic importance of cTnT in hemodialysis patients [22-25,27].

\section{Recent advances \\ Diagnostic value of BNP or NT-pro-BNP for LV systolic dysfunction in hemodialysis patients}

In a recent small study, a serum NT-pro-BNP cutoff $\geq 7200 \mathrm{ng} / \mathrm{L}$ was suggested to be useful in diagnosing LV systolic dysfunction in hemodialysis patients, regardless of the patients' fluid status, with a specificity of $90 \%$ and a sensitivity of $79 \%$. Further reducing the cutoff to approximately $5000 \mathrm{ng} / \mathrm{L}$ increased the sensitivity in diagnosing LV systolic dysfunction to $>90 \%$ but reduced the specificity to $80 \%$ [30]. This observation was very similar to the earlier Cardiovascular Risk Evaluation Extension (CREED) study, suggesting the potential value of BNP testing in ruling out systolic dysfunction in the dialysis population [14]. However, the best cutoff of BNP or NT-pro-BNP in diagnosing or ruling out systolic dysfunction will need stratification according to residual renal function and will require further confirmation in a larger cohort of the dialysis population. Notably, in patients with LV systolic dysfunction, persistent postdialytic volume overload was significantly related to serum levels of NT-pro-BNP [30]. A number of other studies reported similar correlations between markers of hypervolemia and high plasma BNP or NT-pro-BNP $[31,32]$. However, so far there are no convincing data to suggest that BNP or NT-pro-BNP represent useful markers of volume status in hemodialysis patients [16,33].

\section{Prognostic value of baseline BNP and NT-pro-BNP in dialysis patients}

BNP and NT-pro-BNP are increasingly recognized to be powerful predictors of mortality and cardiovascular death in the dialysis population. In one of the earliest prospective cohort studies, performed in 399 hemodialysis patients, NT-pro-BNP was associated with 2-year allcause mortality and, in a smaller study, with 3-year cardiac morbidity and mortality [13]. The CREED study showed that plasma BNP taken on a non-dialysis day was predictive of overall and cardiovascular death in hemodialysis patients [34]. A more recent study by Madsen et al. [16] also showed that both pre- and posthemodialysis NT-pro-BNP were predictive of 2-year mortality. These data clearly suggested that levels of BNP and NT-pro-BNP had powerful prognostic implications irrespective of whether the measurement was taken before, shortly after or in-between dialysis. One study showed that both pre- and post-dialysis BNP and NTpro-BNP were strongly correlated [35]. However, given that levels of BNP and NT-pro-BNP were altered by hemodialysis [16,35], it is important to standardize the timing of measurement of BNP or NT-pro-BNP in relation to the dialysis session in hemodialysis patients.

In peritoneal dialysis patients, NT-pro-BNP was predictive of long-term (3 years) all-cause mortality, cardiovascular death and events as well as cardiovascular congestion independent of echocardiographic measures of LV mass and ejection fraction [15]. Post hoc analysis from the Adequacy of Dialysis in Mexico (ADEMEX) study also showed a similar finding that the baseline NTpro-BNP level was independently predictive of overall survival and cardiovascular death in peritoneal dialysis patients, irrespective of treatment arm [36].

A recent study compared the prognostic value of NT-proBNP and cTnT in hemodialysis patients and showed that 
NT-pro-BNP was strongly correlated with LV systolic dysfunction and was indeed more strongly associated with mortality than cTnT [17]. However, the combination of cTnT and NT-pro-BNP did not improve the association with all-cause and cardiovascular mortality compared to NT-pro-BNP alone. NT-pro-BNP was a marker of mortality even after adjusting for LV mass index and midwall fractional shortening. These data suggest that NT-pro-BNP may be a more powerful prognostic marker compared to cTnT.

\section{Role of serial monitoring of NT-pro-BNP for outcome prediction in dialysis patients}

More recently, a prospective cohort study performed in 2,990 incident hemodialysis patients reported similar findings; increased NT-pro-BNP level was independently associated with increased risk of mortality at 90 days and 1 year [37]. Furthermore, in a smaller subset of 585 incident hemodialysis patients, repeat measurement of NT-pro-BNP was performed at 3 months. Patients with the greatest increase in NT-pro-BNP after 3 months of dialysis showed a 2.4-fold higher risk of mortality than those with the greatest decrease in NT-pro-BNP. These data for the first time suggested that serial changes in NTpro-BNP levels also carried important prognostic information, independent of baseline NT-pro-BNP level, and were predictive of subsequent mortality [37].

Notably, in the recent post hoc analysis of the German Diabetes Dialysis Study (4D Study), which evaluated atorvastatin in 1,255 type 2 diabetic ESRD patients on maintenance hemodialysis, it was found that increased NT-pro-BNP over at least a 6-month period was strongly predictive of an increased risk of sudden death, cardiovascular event and mortality. Doubling of NTpro-BNP was associated with a $46 \%$ increase in the risk of death. Furthermore, the increased risk of mortality with rising NT-pro-BNP was independent of baseline NT-pro-BNP and baseline co-morbidity [38].

Prognostic value of cardiac troponin $T$ in dialysis patients In a recent meta-analysis based on 28 studies published between 1999 and 2004 and including 3,931 patients, cTnT was shown to be a useful risk stratification tool in the ESRD population. The pooled analysis indicated that an elevated cTnT $(>0.1 \mu \mathrm{g} / \mathrm{L})$ is useful in identifying a subgroup of asymptomatic ESRD patients with poor survival and a higher risk of cardiac death [39]. Recently, the Food and Drug Administration has approved the use of cTnT as a biomarker for mortality risk stratification in ESRD patients. Similarly, the use of cTnT for predicting prognosis has also been recommended by the KDOQI [1]. Of note, the NECOSAD (Netherlands Cooperative Study on the Adequacy of Dialysis) showed only limited added predictive power of cTnT over other clinical risk factors in a combined cohort of hemodialysis and peritoneal dialysis patients [40]. This observation was somewhat contrary to our recent finding that cTnT had a significant additional value for prognostication beyond the standard clinical, biochemical, dialysis and echocardiographic measures, including LV mass and ejection fraction in chronic peritoneal dialysis patients [41]. More importantly, our study showed that the prognostic value of cTnT was independent of inflammation, residual renal function, LV hypertrophy and dysfunction, clearly supporting the additional value of measuring cTnT for early identification of high-risk ESRD patients. A recent study also showed that cTnT is a useful biomarker in predicting the development of circulatory congestion in chronic peritoneal dialysis patients [42]. These data suggest that cTnT serves as an important adjunct to echocardiography in identifying peritoneal dialysis patients at risk of circulatory congestion. Whether the findings are also applicable to hemodialysis patients requires further evaluation.

\section{Mechanisms of elevated cTnT in dialysis patients}

Elevated cTnT has been linked to LV hypertrophy, LV dilation, diabetes, and impaired systolic and diastolic dysfunction in hemodialysis patients [43-45]. There is evidence that elevated cTnT in asymptomatic ESRD patients reflects subclinical myocardial injury. Ooi et al. [46] showed that elevated cTnT was invariably associated with pathological evidence of old, recent or healing myocardial necrosis or micro-infarction. In another study, cTnT elevation was closely correlated with the severity of angiographic coronary artery disease in chronic hemodialysis patients [47]. cTnT elevation has also been linked to the degree of coronary artery calcification in asymptomatic hemodialysis patients [48]. Even though cTnT was significantly confounded by residual kidney function [41], circulating cTnT in patients with kidney failure was noted to be predominantly the free-intact form, as in patients with acute coronary syndrome [49]. This was important evidence to support that circulating CTnT in ESRD patients is indeed a marker of cardiac pathology. Given that free and bound cTnT are both relatively large molecules of 37 and $77 \mathrm{kDa}$, respectively, elevated cTnT in ESRD patients is unlikely to be the result of decreased renal clearance. Using contrast magnetic resonance imaging, a recent study showed that elevated cTnT cannot be solely attributed to previous subclinical myocardial necrosis or LV hypertrophy [50]. It was speculated that additional myocardial pathologies, such as myocardial fibrosis, may contribute to increased cTnT in ESRD patients and require further evaluation. 


\section{Implications for clinical practice Clinical utility of BNPINT-pro-BNP in hemodialysis patients}

Together, these data suggest that serial monitoring of NTpro-BNP levels may represent a novel and useful clinical tool in guiding treatment efficacy in the dialysis population and warrant further investigation. Treatment guided by lowering plasma NT-pro-BNP levels has been shown to reduce cardiovascular events and delay time to first cardiovascular event, compared with usual clinically guided treatment in patients with chronic heart failure [51]. A BNP-guided strategy has also been shown to reduce the risk of heart-failure related death or length of hospital stay for heart failure, compared to standard clinical care in the general population [52]. In a recent small prospective study of 21 stable hemodialysis patients with preserved systolic function, changes in $\mathrm{LV}$ mass index over 6-month and 12-month periods were closely correlated with changes in NT-pro-BNP levels [53]. All these observations prompt further investigation into the application of serial BNP and NT-pro-BNP monitoring as biomarkers for assessing changes in $\mathrm{LV}$ mass index or systolic function in hemodialysis patients. Whether BNP or NT-pro-BNP guided therapy may be useful in monitoring treatment efficacy and improving clinical outcomes of hemodialysis patients needs further prospective evaluation.

\section{Clinical utility of cTnT in hemodialysis patients}

How can cTnT testing be applied in daily clinical practice? Given that cTnT is confounded by residual kidney function, we believe a baseline level should first be obtained in all hemodialysis patients in order to distinguish subsequent cTnT elevation due to acute coronary syndrome and/or chronic myocardial injury. The measurement should best be obtained before dialysis because cTnT levels may increase post-dialysis [54]. A baseline level not only allows outcome prediction and identifies high-risk patients, but also forms an important basis to evaluate changes over time. Our recent data suggested that even minimally increased cTnT is associated with an increased risk of mortality and cardiovascular death in peritoneal dialysis patients [41]. This is well in accord with observations in the general population suggesting that a minimally increased cTnT concentration reflects increased cardiovascular risk [55]. According to the recent National Academy of Clinical Biochemistry (NACB) laboratory medicine practice guidelines, measurement of cardiac troponins should also be used to evaluate acute coronary syndrome in ESRD patients [56]. In ESRD patients who present with possible acute coronary syndrome, a dynamic change in cardiac troponins of $\geq 20 \%$ after presentation should be used to define acute coronary syndrome. In addition, testing for cardiac troponins may be used as an aid in defining the risk of mortality in ESRD patients. Whether cTnT testing may be a useful screening test for cardiovascular disease in the hemodialysis population warrants further evaluation.

\section{Abbreviations}

$\mathrm{BNP}$, brain natriuretic peptide; CKD, chronic kidney disease; CREED, Cardiovascular Risk Evaluation Extension; CTnT, cardiac troponin T; ESRD, end-stage renal disease; KDOQI, Kidney Disease Outcome Quality Initiative; LV, left ventricular; NT-pro-BNP, N-terminalpro-brain natriuretic peptide.

\section{Competing interests}

The author declares that she has no competing interests.

\section{References}

I. K/DOQI Workgroup: K/DOQI clinical practice guidelines for cardiovascular disease in dialysis patients. Am J Kidney Dis 2005, 45 (Suppl 3): I6-153.

2. Yasue $H$, Yoshimura M, Sumida $H$, Kikuta K, Kugiyama K, Jougasaki $M$, Ogawa H, Okumura K, Mukoyama M, Nakao K: Localization and mechanism of secretion of B-type natriuretic peptide in comparison with those of A-type natriuretic peptide in normal subjects and patients with heart failure. Circulation 1994, 90:195-203.

3. Hosoda K, Nakao K, Mukoyama M, Saito Y, Jougasaki M, Shirakami G, Suga SI, Ogawa Y, Yasue H, Imura H: Expression of brain natriuretic peptide gene in human heart: production in the ventricle. Hypertension 1991, I7:1 152-5.

4. Kinnunen $\mathrm{P}$, Vuolteenaho $\mathrm{O}$, Ruskoaho $\mathrm{H}$ : Mechanisms of atrial and brain natriuretic peptide release from rat ventricular myocardium: effect of stretching. Endocrinology 1993, I32:196|-70.

5. Yamamoto K, Burnett J, Jougasaki M, Nishimura RA, Bailey KR, Saito Y, Nakao K, Redfield MM: Superiority of brain natriuretic peptide as a hormonal marker of ventricular systolic and diastolic dysfunction and ventricular hypertrophy. Hypertension 1996, 28:988-94.

6. Maisel AS, Krishnaswamy P, Nowak RM, McCord J, Hollander JE, Duc P, Omland T, Storrow AB, Abraham WT, Wu AH, Clopton P, Steg PG, Westheim A, Knudsen CW, Perez A, Kazanegra R, Herrmann HC, McCullough PA: Rapid measurement of B-type natriuretic peptide in the emergency diagnosis of heart failure. N Engl J Med 2002, 347:161-7.

7. Hunt PJ, Richards AM, Nicholls MG, Yandle TG, Doughty RN, Espiner EA: Immunoreactive amino-terminal pro-brain natriuretic peptide (NT-PROBNP): a new marker of cardiac impairment. Clin Endocrinol (Oxf) 1997, 47:287-96.

8. Battaglia M, Pewsner D, Juni P, Egger M, Bucher HC, Bachmann LM: Accuracy of $B$-type natriuretic peptide tests to exclude congestive heart failure: systematic review of test accuracy studies. Arch Intern Med 2006, I 66:1073-80.

9. Januzzi JL Jr, Camargo CA, Anwaruddin S, Baggish AL, Chen AA, Krauser DG, Tung R, Cameron R, Nagurney JT, Chae CU, Lloyd-Jones DM, Brown DF, Foran-Melanson S, Sluss PM, Lee-Lewandrowski E, Lewandrowski KB: The N-terminal Pro-BNP investigation of dyspnea in the emergency department (PRIDE) study. Am J Cardiol 2005, 95:948-54.

10. McCullough PA, Nowak RM, McCord J, Hollander JE, Herrmann HC, Steg PG, Duc P, Westheim A, Omland T, Knudsen CW, Storrow AB, Abraham WT, Lamba S, Wu AH, Perez A, Clopton P, Krishnaswamy P, Kazanegra R, Maisel AS: B-type natriuretic peptide and clinical judgment in emergency diagnosis of heart failure: analysis 
from Breathing Not Properly (BNP) Multinational Study. Circulation 2002, 106:416-22.

11. Anwaruddin S, Lloyd-Jones DM, Baggish A, Chen A, Krauser D, Tung $R$, Chae C, Januzzi JL Jr: Renal function, congestive heart failure, and amino-terminal pro-brain natriuretic peptide measurement: results from the ProBNP Investigation of Dyspnea in the Emergency Department (PRIDE) Study. J Am Coll Cardiol 2006, 47:9|-7.

12. Kragelund C, Gronning B, Kober L, Hildebrandt P, Steffensen R: $\mathrm{N}$-terminal pro-B-type natriuretic peptide and long-term mortality in stable coronary heart disease. N Engl ] Med 2005, 352:666-75.

13. Apple FS, Murakami MM, Pearce LA, Herzog CA: Multi-biomarker risk stratification of $\mathrm{N}$-terminal pro-B-type natriuretic peptide, high-sensitivity C-reactive protein, and cardiac troponin $\mathbf{T}$ and $\mathrm{I}$ in end-stage renal disease for all-cause death. Clin Chem 2004, 50:2279-85.

14. Mallamaci F, Zoccali C, Tripepi G, Benedetto FA, Parlongo S, Cataliotti A, Cutrupi S, Giacone G, Bellanuova I, Stancanelli B, Malatino LS: Diagnostic potential of cardiac natriuretic peptides in dialysis patients. Kidney Int 200I, 59:1559-66.

15. Wang AY, Lam CW, Yu CM, Wang M, Chan IH, Zhang Y, Lui SF, Sanderson JE: N-terminal pro-brain natriuretic peptide: an independent risk predictor of cardiovascular congestion, mortality, and adverse cardiovascular outcomes in chronic peritoneal dialysis patients. J Am Soc Nephrol 2007, I8:32I-30.

16. Madsen LH, Ladefoged S, Corell P, Schou M, Hildebrandt PR, Atar D: $\mathbf{N}$-terminal pro brain natriuretic peptide predicts mortality in patients with end-stage renal disease in hemodialysis. Kidney Int 2007, $71: 548-54$.

17. Satyan S, Light RP, Agarwal R: Relationships of $\mathbf{N}$-terminal pro-Bnatriuretic peptide and cardiac troponin $T$ to left ventricular mass and function and mortality in asymptomatic hemodialysis patients. Am J Kidney Dis 2007, 50:1009-19.

18. Sommerer C, Giannitsis E, Schwenger V, Zeier M: Cardiac biomarkers in haemodialysis patients: the prognostic value of amino-terminal pro-B-type natriuretic peptide and cardiac troponin T. Nephron Clin Pract 2007, 107:c77-81.

19. Roberts MA, Srivastava PM, Macmillan N, Hare DL, Ratnaike S, Sikaris $\mathrm{K}$, lerino FL: B-type natriuretic peptides strongly predict mortality in patients who are treated with long-term dialysis. Clin J Am Soc Nephrol 2008, 3:1057-65.

20. Luchner A, Hengstenberg C, Lowel H, Riegger GAJ, Schunkert H, Holmer S: Effect of compensated renal dysfunction on approved heart failure markers: Direct comparison of brain natriuretic peptide (BNP) and N-terminal pro-BNP. Hypertension 2005, 46: II8-23.

21. deFilippi CR, Fink JC, Nass CM, Chen H, Christenson R: N-terminal pro-B-type natriuretic peptide for predicting coronary disease and left ventricular hypertrophy in asymptomatic CKD not requiring dialysis. Am J Kidney Dis 2005, 46:35-44.

22. Ooi DS, House AA: Cardiac troponin $\mathbf{T}$ in hemodialyzed patients. Clin Chem 1998, 44:1410-6.

23. Dierkes J, Domrose U, Westphal S, Ambrosch A, Bosselmann HP, Neumann KH, Luley C: Cardiac troponin T predicts mortality in patients with end-stage renal disease. Circulation 2000, 102:1964-9.

24. Deegan PB, Lafferty ME, Blumsohn A, Henderson IS, McGregor E: Prognostic value of troponin $T$ in hemodialysis patients is independent of comorbidity. Kidney Int 200I, 60:2399-405.

25. Conway B, McLaughlin M, Sharpe P, Harty J: Use of cardiac troponin $\mathrm{T}$ in diagnosis and prognosis of cardiac events in patients on chronic haemodialysis. Nephrol Dial Transplant 2005, 20:2759-64

26. Apple FS, Murakami MM, Pearce LA, Herzog CA: Predictive value of cardiac troponin I and $\mathrm{T}$ for subsequent death in end-stage renal disease. Circulation 2002, 106:294|-5.

27. Ishii J, Nomura M, Okuma T, Minagawa T, Naruse H, Mori Y, Ishikawa T, Kurokawa H, Hirano T, Kondo T, Nagamura Y, Ezaki K, Hishida H:
Risk stratification using serum concentrations of cardiac troponin $T$ in patients with end-stage renal disease on chronic maintenance dialysis. Clin Chim Acta 200I, 3 I 2:69-79.

28. Abbas NA, John RI, Webb MC, Kempson ME, Potter AN, Price CP, Vickery S, Lamb E): Cardiac troponins and renal function in nondialysis patients with chronic kidney disease. Clin Chem 2005, 5 I:2059-66.

29. Aviles RJ, Askari AT, Lindahl B, Wallentin L, Jia G, Ohman EM, Mahaffey KW, Newby LK, Califf RM, Simoons ML, Topol E], Berger P, Lauer MS: Troponin T levels in patients with acute coronary syndromes, with or without renal dysfunction. $N$ Engl J Med 2002, 346:2047-52.

30. David S, Kumpers P, Seidler V, Biertz F, Haller H, Fliser D: Diagnostic value of $\mathrm{N}$-terminal Pro-B-Type natriuretic peptide (NT-ProBNP) for left ventricular dysfunction in patients with chronic kidney disease stage 5 on haemodialysis. Nephrol Dial Transplant 2008, 23:1370-7.

3I. Fagugli RM, Palumbo B, Ricciardi D, Pasini P, Santirosi P, Vecchi L, Pasticci F, Palumbo R: Association between brain natriuretic peptide and extracellular water in hemodialysis patients. Nephron Clin Pract 2003, 95:c60-c66.

32. Lee SW, Song JH, Kim GA, Lim HJ, Kim MJ: Plasma brain natriuretic peptide concentration on assessment of hydration status in hemodialysis patient. Am J Kidney Dis 2003, 41:1257-66.

33. Sheen $V$, Bhalla $V$, Tulua-Tata A, Bhalla MA, Weiss D, Chiu A, Abdeen $O$, Mullaney S, Maisel A: The use of B-type natriuretic peptide to assess volume status in patients with end-stage renal disease. Am Heart J 2007, I 53:244, el-5.

34. Zoccali C, Mallamaci F, Benedetto FA, Tripepi G, Parlongo S, Cataliotti A, Cutrupi S, Giacone G, Bellanuova I, Cottini E, Malatino LS: Cardiac natriuretic peptides are related to left ventricular mass and function and predict mortality in dialysis patients. J Am Soc Nephrol 200I, I2:1508-I5.

35. Racek J, Kralova H, Trefil L, Rajdl D, Eiselt J: Brain natriuretic peptide and $\mathrm{N}$-terminal proBNP in chronic haemodialysis patients. Nephron Clin Pract 2006, 103:c162.

36. Paniagua R, Amato D, Mujais S, Vonesh E, Ramos A, Correa-Rotter R, Horl WH: Predictive value of brain natriuretic peptides in patients on peritoneal dialysis: results from the ADEMEX trial. Clin J Am Soc Nephrol 2008, 3:407-15.

FI000 Factor 4.8 Must Read

Evaluated by Angela Yee-Moon Wang 29 Jan 2008, Thomas Golper 16 Jul 2008

37. Gutierrez OM, Tamez H, Bhan I, Zazra J, Tonelli M, Wolf M, Januzzi JL, Chang $Y$, Thadhani R: N-terminal pro-B-type natriuretic peptide (NT-pro-BNP) concentrations in hemodialysis patients: prognostic value of baseline and follow-up measurements. Clin Chem 2008, 54:1339-48.

38. Winkler K, Wanner C, Drechsler C, Lilienthal J, Marz W, Krane V; for the German Diabetes and Dialysis Study Investigators: Change in Nterminal-pro-B-type-natriuretic peptide and the risk of sudden death, stroke, myocardial infarction, and all-cause mortality in diabetic dialysis patients. Eur Heart J 2008, 29:2092-9.

39. Khan NA, Hemmelgarn BR, Tonelli M, Thompson CR, Levin A: Prognostic value of troponin $T$ and $I$ among asymptomatic patients with end-stage renal disease: a meta-analysis. Circulation 2005, I I 2:3088-96.

40. Havekes B, van Manen JG, Krediet RT, Boeschoten EW, Vandenbroucke JP, Dekker FW: Serum troponin T concentration as a predictor of mortality in hemodialysis and peritoneal dialysis patients. Am J Kidney Dis 2006, 47:823-9.

4I. Wang AY, Lam CW, Wang M, Chan IH, Goggins WB, Yu CM, Lui SF, Sanderson JE: Prognostic value of cardiac troponin $\mathbf{T}$ is independent of inflammation, residual renal function, and cardiac hypertrophy and dysfunction in peritoneal dialysis patients. Clin Chem 2007, 53:882-9.

42. Wang AY, Lam CW, Yu CM, Wang M, Chan IH, Lui SF, Sanderson JE: Troponin $\mathrm{T}$, left ventricular mass, and function are excellent 
predictors of cardiovascular congestion in peritoneal dialysis. Kidney Int 2006, 70:444-52.

43. Mallamaci F, Zoccali C, Parlongo S, Tripepi G, Benedetto FA, Cutrupi S, Bonanno G, Fatuzzo P, Rapisarda F, Seminara G, Stancanelli B, Bellanuova I, Cataliotti A, Malatino LS: Troponin is related to left ventricular mass and predicts all-cause and cardiovascular mortality in hemodialysis patients. Am J Kidney Dis 2002, 40:68-75.

44. Iliou MC, Fumeron C, Benoit MO, Tuppin P, Courvoisier CL, Calonge VM, Moatti N, Buisson C, jacquot C: Factors associated with increased serum levels of cardiac troponins $T$ and $I$ in chronic haemodialysis patients: Chronic Haemodialysis And New Cardiac Markers Evaluation (CHANCE) study. Nephrol Dial Transplant 200I, 16:1452-8.

45. Sharma R, Gaze DC, Pellerin D, Metha R, Gregson H, Streather CP, Collinson PO, Brecker SJ: Cardiac structural and functional abnormalities in end stage renal disease patients with elevated troponin T. Heart 2006, 92:804-9.

46. Ooi DS, Isotalo PA, Veinot JP: Correlation of antemortem serum creatine kinase, creatine kinase-MB, troponin I, and troponin T with cardiac pathology. Clin Chem 2000, 46:338-44.

47. deFilippi C, Wasserman S, Rosanio S, Tiblier E, Sperger H, Tocchi M, Christenson R, Uretsky B, Smiley M, Gold J, Muniz H, Badalamenti J, Herzog C, Henrich W: Cardiac troponin $T$ and C-reactive protein for predicting prognosis, coronary atherosclerosis, and cardiomyopathy in patients undergoing long-term hemodialysis. JAMA 2003, 290:353-9.

48. Jung $\mathrm{HH}, \mathrm{Ma} \mathrm{KR}$, Han $\mathrm{H}$ : Elevated concentrations of cardiac troponins are associated with severe coronary artery calcification in asymptomatic haemodialysis patients. Nephrol Dial Transplant 2004, 19:3117-23.

49. Fahie-Wilson MN, Carmichael DJ, Delaney MP, Stevens PE, Hall EM, Lamb EJ: Cardiac troponin T circulates in the free, intact form in patients with kidney failure. Clin Chem 2006, 52:4I4-20.

50. deFilippi CR, Thorn EM, Aggarwal M, Joy A, Christenson RH, Duh SH, Jeudy J, Beache G: Frequency and cause of cardiac troponin $\mathrm{T}$ elevation in chronic hemodialysis patients from study of cardiovascular magnetic resonance. Am J Cardiol 2007, 100:885-9.

5I. Troughton RW, Frampton CM, Yandle TG, Espiner EA, Nicholls MG, Richards AM: Treatment of heart failure guided by plasma aminoterminal brain natriuretic peptide (N-BNP) concentrations. Lancet 2000, 355: I | 26-30

52. Jourdain P, Jondeau G, Funck F, Gueffet P, Le HA, Donal E, Aupetit JF, Aumont MC, Galinier M, Eicher JC, Cohen-Solal A, Juilliere Y: Plasma brain natriuretic peptide-guided therapy to improve outcome in heart failure: the STARS-BNP Multicenter Study. J Am Coll Cardiol 2007, 49:1733-9.

FI000 Factor 3.0 Recommended Evaluated by Lynne Warner Stevenson

53. Choi SY, Lee JE, Jang EH, Kim MO, Baek H, Ki CS, Park SW, Kim DJ, Huh WS, Oh HY, Kim YG: Association between changes in $\mathbf{N}$-terminal pro-brain natriuretic peptide levels and changes in left ventricular mass index in stable hemodialysis patients. Nephron Clin Pract 2008, I I0:C93-CI00.

54. Wayand D, Baum H, Schatzle G, Scharf J, Neumeier D: Cardiac troponin $\mathbf{T}$ and $I$ in end-stage renal failure. Clin Chem 2000, 46: $1345-50$.

55. Wallace TW, Abdullah SM, Drazner MH, Das SR, Khera A, McGuire DK, Wians F, Sabatine MS, Morrow DA, de Lemos JA: Prevalence and determinants of troponin $T$ elevation in the general population. Circulation 2006, I I 3:1958-65.

56. Wu AH, Jaffe AS, Apple FS, Jesse RL, Francis GL, Morrow DA, Newby LK, Ravkilde J, Tang WH, Christenson RH, Cannon CP: National Academy of Clinical Biochemistry Laboratory Medicine Practice Guidelines: use of cardiac troponin and B-type natriuretic peptide or $\mathrm{N}$-terminal proB-type natriuretic peptide for etiologies other than acute coronary syndromes and heart failure. Clin Chem 2007, 53:2086-96. 